\title{
The Effect of Sports Physical Loads on the Somatic Development and Physical Performance of Young Football and Basketball Players
}

\author{
Angelina Shakhanova*, Andrey Kuzmin, Svetlana Grechishkina, Nina Khasanova \\ and Ekaterina Kalnaya \\ Adyghe State University (AGU), Maikop, Russia Federation; \\ monblan.pro@yandex.ru
}

\begin{abstract}
The experiment was performed in a longitudinal mode at the premises of the Children and Youth Sports School of the Olympic Reserve (CYSSOR). A total of 60 boys playing football and 60 boys playing basketball at the age of 10-15 years were examined. The control group consisted of 60 10-15-year-old schoolboys not engaged in sports activities. Todetermine PWC170 and V02max, the hardware and software system "Poli-Spektr-Ergo" (Neurosoft, Ivanovo) was used. The load with the power of PWC170 was simulated on a cycle ergometer under the ECG control. It has been shown that the genetically determined regularities of ontogeny are less constant and stable in their time-response and quantitative characteristics. Under sufficiently durable and strong effects of the athletic loads, a time displacement of the adolescent growth spurt occurs towards the earlier or later age periods (towards the age of 12 years in young basketball players, and 14 years in young football players against the age of 13 years, which is naturally predetermined by the ontogeny process in boys). In the conditions of football training, the sports physical activities can be considered as a growth promoting factor only in the early stages of the training process (10-11 years). The further growth promoting influence is leveled by the increasing volume and intensity of sports physical activities. The age dynamics of PWC170 and V02max in the young football players and male non-athletes is closely connected with the dynamics of somatic development: During the periods of the increasing growth rates, the PWC170 and V02max indicators are reduced, and during the periods when the growth rates are inhibited - these indicators start increasing, which proves the objectivity of processes, such as the heterochrony, as well as the critical and sensitive periods.
\end{abstract}

Keywords: Athletic Loads, PWC170, Somatic Development, V02max, Young Basketball Players, Young Football Players

\section{Introduction}

The development of sports activities for children as a means of health strengthening among the younger generation makes the issue of the physical activity adequacy especially topical. The purposeful and longterm implementation of physical exercises during the day regimen of a child has a significant impact on the processes of growth and development of an organism, and contributes to the formation of the specialized morphological and functional pattern characteristics.
Playing football and basketball is an appropriate pattern for studying special aspects of the functional-adaptive state of the body of children and adolescents engaged in physical activities. The training and competitive activity in the game sports, especially in football, requires performing a much larger volume of speed-power and self-power loads as well as the enhanced development of the general and speed endurance. Already at the early stages of athletic performance, the training process of young football players includes a large number of training, control, and competitive games with the high motor density. Such training process

\footnotetext{
${ }^{*}$ Author for correspondence
} 
requires a rigid medical and biological control. A coach should know how the changes in the morphofunctional status of the body of young athletes occurs over age, and based on this knowledge, determine the current functional-adaptive state, physical fitness, and adaptation strategy for young athletes. In this regard, it becomes necessary to establish a probable profile of the morpho-functional status of young athletes at the regular football and basketball trainings, which will help to solve the problems of health promotion and preservation, as well as the sportsmanship improvement.

At the same time, it should be considered that the adaptation to physical loads imposes specific requirements to the energy segment, as well as to the muscular and cardio-respiratory systems. Being the most integrative and informative indicators of energy balance and functional state of the cardio-respiratory and muscular systems, the quantitative indicators of $\mathrm{PWC}_{170}$ and $\mathrm{VO}_{2}$ max precisely characterize the physical and aerobic performance and the reserves of the oxygen supply systems, and allow determining the individual level of physical fitness of a tested person ${ }^{1,2}$. The high level of the $\mathrm{PWC}_{170}$ and $\mathrm{VO}_{2} \max$ indicators is the key to the potential physical capacity of the body. Thus, the assessment of their parameters should be used as the basis for individual health-enhancing physical training. In order to determine the personal level of adaptation and performance, and prepare appropriate recommendations on improving the current functional state of the body, it is necessary to determine the level of contingency with the rates of somatic development of the body.

\section{Research Organization and Methods}

The experiment was carried out in a longitudinal mode on the same children and adolescents regularly going in for sports at sports clubs of the Children and Youth Sports School of the Olympic Reserve (CYSSOR) in Maykop.

A total of 60 boys playing football and 60 boys playing basketball at the age of 10-15 years were examined. The control group consisted of 60 10-15-year-old schoolboys studying at the secondary school No. 7 with the traditional motor mode (2 classroom hours of physical culture per week). The total number of the study subjects constituted 180 children and adolescents.

The practically healthy children voluntarily participated in the experiment with the parents' informed consent. The study was carried out in compliance with the ethical norms of physiological research.

All the studies were conducted before noon (9:0012:00 $\mathrm{AM})$ at a comfort temperature $\left(18-20^{\circ} \mathrm{C}\right)$ at the premises of the "Physiology of Child Development" laboratory at the Research Institute of Comprehensive Problems of the Adyghe State University.

The examination took place twice per year-in autumn (October-November) and in spring (March-April), since these seasons are characterized by an optimal level of adaptation to physical activities, or alternatively, by the growing fatigue in the event of the irrationally organized trainings.

The training process within the CYSSOR mode involved a stepwise increase in the number of training hours per week (from 6 to 10 hours). Throughout the entire training process, 1,030 hours were devoted to the general physical training of the young football players; and 447 and 2,500 hours were provided for the special and technical-tactical training, accordingly. The training mode provided for the gradual increase of the study time dedicated to the general (2.2-fold), technicaltactical (2.9-fold), and special (4.8-fold) training for the period starting from sports specialization (9-10 years of age) and up to the advanced training stage (14-15 years of age).

At the initial stage of training young football players (aged 10-11), the loads of high intensity and long duration were excluded from the training course. Since the age of 12-13 years, greater loads with high intensity and motor density (up to $90 \%$ ) were introduced to the training mode of the young football players in order to develop general and speed endurance.

The structure of both training and competitive activities in basketball is somewhat different from football. In basketball, general physical training is given 3.3 times less training time, than in football; special training - 1.3 times less, and technical-tactical and integrated training-1.1 times less. If during the first year of basketball training, much attention is paid to the general physical training (25\% of the academic time), then during the final stages of the learning process, the focus is made on technical-tactical and integral training, while the 4 share of the general physical training is just $8 \%$ of the academic time (compared to $21 \%$ in football). In general, the volume of competitive activities in football is 2.5 times higher than in basketball. 
The assessment of the physical performance and general endurance of the bodies of the young football and basketball players included:

- Determination of physical performance via the PWC $_{170}$ test.

- Determination of the maximum oxygen consumption ( $\left.\mathrm{VO}_{2} \max \right)$.

In order to determine the $\mathrm{PWC}_{170}$ value, we used the hardware and software system "Poli-Spektr-Ergo" of the Neurosoft Company (Ivanovo). The load with the power of $\mathrm{PWC}_{170}$ was simulated on a cycle ergometer under the ECG control (the "Poli-Spektr-12" electrocardiograph). The indicators of maximum oxygen consumption $\left(\mathrm{VO}_{2} \max \right)$ were determined through the direct method using an automated gas analyzer, which, during the load application, allowed continuously recording the oxygen and carbon dioxide concentrations in an exhaled air flow. The tested persons gradually increased the load on a cycle ergometer. The initial muscular load and the subsequent "steps" were selected with account of the gender, age, and physical fitness of the tested person. Calculation of the $\mathrm{PWC}_{170}$ and $\mathrm{VO}_{2}$ max values in relative units per kilogram of body weight was carried out automatically by the "PoliSpektr" program.

The statistical processing of the test results was performed using the STATISTICA 6.0 software package.

\section{Results and Discussion}

It has been found that the somatic development of boys aged 10-15 years, regardless of the motor activity mode, was characterized by the synchronization of the body length and weight growth rates. This is an important and essential factor of the harmonious development of the body, and provision of its sustainable performance.

The highest rates of length and weight growth in the boys not engaged in sports activities were observed at the age of 10-13 years, reaching the maximum values at the age of 13 years (Table 1). Subsequently, the body length and weight growth rates decreased reaching their lowest values at the age of 15 years.

The periods of the growth rate increase and slowdown do not coincide in time in the young football players and the boys that not engaged in sports activities. In the young football players aged 12 and 13 years, the processes of growth slow down a little bit, and their adolescent spurt is shifted to a later period of 14 years (Table 1 ).

The somatic development of male basketball players during the ontogeny demonstrates unidirectional but less contiguous, than in young football players, dynamics of the body length and weight growth rates. The age of 11 and 14 years in young basketball players is characterized by the lowest growth rates of the body length and weight.

Table 1. The $(\mathrm{M} \pm \mathrm{m})$ indicators of somatic development of the 10-15-year-old boys, who were and were not engaged in sports activities (football, basketball)

\begin{tabular}{|c|c|c|c|c|c|c|}
\hline \multirow[t]{2}{*}{ Age } & \multicolumn{2}{|c|}{ Non-athletes } & \multicolumn{2}{|c|}{ Football players } & \multicolumn{2}{|c|}{ Basketball players } \\
\hline & Body length $_{(\mathrm{SM})}$ & Body weight $_{(\mathrm{KG})}$ & Body length $_{(\mathrm{SM})}$ & Body weight $_{(\mathrm{KG})}$ & Body length $_{(\mathrm{SM})}$ & Body weight $_{(\mathrm{KG})}$ \\
\hline 10 years & $138.0 \pm 0.4$ & $33.0 \pm 0.5$ & $* * 152.0 \pm 1.3$ & $* * 40.0 \pm 0.3$ & $* \star 146.2 \pm 1.4^{\star \star}$ & $* * 40.7 \pm 0.6$ \\
\hline 11 years & $142.0 \pm 0.3$ & $35.5 \pm 0.2$ & ${ }^{* *} 156.3 \pm 1.4$ & $* * 43.0 \pm 0.6$ & ${ }^{\star *} 149.0 \pm 1.0^{\star \star}$ & *38.5 $\pm 0.7^{\star}$ \\
\hline Growth rate $_{( \pm \%)}$ & $+2.9 \%$ & $+7.5 \%$ & $+2.9 \%$ & $+7.5 \%$ & +1.9 & $-5.3 \%$ \\
\hline 12 years & $148.3 \pm 0.2$ & $39.3 \pm 0.5$ & $* * 156.6 \pm 1.0$ & $\star * 44.1 \pm 0.4$ & $\star * 160.4 \pm 0.5^{\star *}$ & $\star * 48.9 \pm 0.8^{\star *}$ \\
\hline Growth rate $_{( \pm \%)}$ & $+4.5 \%$ & $10.8 \%$ & $+0.2 \%$ & $+2.6 \%$ & +7.7 & $+27.1 \%$ \\
\hline 13 years & $159.3 \pm 0.1$ & $45.0 \pm 0.4$ & ${ }^{\star} 156.9 \pm 0.5$ & $45.5 \pm 0.4$ & ${ }^{\star \star} 168.4 \pm 0.5^{\star \star}$ & $\star \star 57.1 \pm 0.8^{\star \star}$ \\
\hline Growth rate $_{( \pm \%)}$ & $+7.4 \%$ & $+14.4 \%$ & $+0.2 \%$ & $+3.3 \%$ & +4.9 & $+16.8 \%$ \\
\hline 14 years & $164.7 \pm 0.1$ & $48.3 \pm 0.2$ & $163.9 \pm 0.5$ & $\star 50.7 \pm 0.5$ & $\star \star * 172.2 \pm 1.0^{\star *}$ & $\star \star x 59.5 \pm 0.4^{\star \star}$ \\
\hline Growth rate $_{(+\%)}$ & $+3.3 \%$ & $+7.4 \%$ & $+4.5 \%$ & $+11.3 \%$ & +2.3 & $+4.1 \%$ \\
\hline 15 years & $169.0 \pm 0.6$ & $51.3 \pm 0.3$ & $168.0 \pm 1.0$ & $51.6 \pm 0.8$ & ${ }^{\star *} 175.2 \pm 0.9^{\star \star}$ & ${ }^{* *} 61.0 \pm 1.1^{\star *}$ \\
\hline Growth rate $_{( \pm \%)}$ & $+2.6 \%$ & $+6.0 \%$ & $+2.5 \%$ & $+1.8 \%$ & $+1.7 \%$ & $+2.5 \%$ \\
\hline $\begin{array}{l}\mathrm{n}-\text { number of } \\
\text { measurements }\end{array}$ & \multicolumn{2}{|c|}{60} & \multicolumn{2}{|c|}{60} & \multicolumn{2}{|c|}{60} \\
\hline
\end{tabular}

Note: (To the right) - significance of differences $(\mathrm{p}<0.05)^{\star},(\mathrm{p}<0.01)^{\star *}$ between the indicators of the young football and basketball players; (To the right) significance of differences $(p<0.05)^{*}$ between the indicators of the young athletes and non-athletes. 
Weight loss at the age of 14 years is an alarming symptom of deconditioning, a sign of high tension of the energy saving mechanisms. At the same time, the highest growth rates of length, and especially of body weight in young basketball players were recorded at the age of 12 years $(+7.7 \%,+27.1 \% \mathrm{P}<0.0$, accordingly). This means that the adolescent growth spurt in boys playing basketball is shifted to an earlier period-the age of 12 years.

The identified regularities stay within the concept of ${ }^{3}$ stating that the processes of growth and differentiation during the course of development are usually dispersed in space or in time. The compliance with this principle logically leads to the irregularity and heterochrony of development. At the same time, the excessive in its intensity and volume systematic muscular activity, followed by the frequent and durable tension of the humoral system ${ }^{4}$, leads to the age-related changes in the basal metabolism and to the time displacement of its nodal and critical periods.

Despite the fact that during all the studied periods, the male non-athletes demonstrated the lowest body weight indicators as compared to their peers engaged in sports activities (Table 1.), in all the examined schoolboys within the age range of 10-15 years, Quetelet index of the body weight and length remained within the age-sex norm, varying over age from $239.1 \pm 0.2 \mathrm{~g} / \mathrm{cm}$ in male nonathletes to $348.2 \pm 0.2 \mathrm{~g} / \mathrm{cm}$ in male basketball players. This points to the balanced nature of development, and has a positive effect on the behavior of all most important functions of the body, their efficiency and stress resistance.

A comparative analysis of the absolute body length indicators within the population of schoolboys showed that at the beginning, male football players had the highest body length indicators, and then, starting from the age of 13 , these indicators changed to the lowest ones (Table 1). Given the fact that the big motor density, the extensive use of speed-power and actual-power loads with the high intensity, is an essential component of any academic training classes in football, it is quite natural for hormones and proteins to switch from the plastic processes to the energy ones in the presence of high stress of the energy supplying mechanisms of muscular activity. As a consequence, the rates of the somatic development and body length definitive indicators decline as compared to the young basketball players and non-athletes.

According to the concept put forward by individual researchers, the impact of sports physical activities on the growth and harmonious development can be in one case neutral, and in another case-promote or inhibit growth ${ }^{5}$. According to the modern theory of genetic control, each child is inherent in a genetically determined channel of development. Under the favorable environmental conditions (optimal physical activities, balanced diet, and rational day regimen), the individual development of a child is displaced to a higher level; and in the case of the sports hyperkinesia or, conversely, hypodynamia occurred due to an abrupt increase of the static component within a child's behavior, especially in the period of intensive growth, the organism passes to a lower level of development within its genetic program. In terms of this discussion, our findings suggest that the sports physical activity in the conditions of football training can be considered as the promoting growth only in the early stages of the training process. Meanwhile, the basketball classes have a growth-promoting effect on the body of young athletes throughout the studied period (10-15 years). The clearest manifestation of this fact was observed in the age range from 12 to 15 years, when the male basketball players had the highest body length indicators as compared to their peers-football players and nonathletes (Table1). In her longitudinal studies ${ }^{4}$, obtained similar data on the regularities of somatic development among the young football and basketball players that were trained 18 hours per week. The $\mathrm{PWC}_{170}$ and $\mathrm{VO}_{2} \max$ values are the primary integral indicators of the cardiorespiratory system efficiency, which reflect the aerobic capacity, physical performance, general endurance, and physical state of the body. The $\mathrm{VO}_{2} \max$ volume reduced to $25 \mathrm{ml} / \mathrm{kg} / \mathrm{min}$ indicates health aggravation and an unfavorable period for the athletic performance. The studies have shown that alongside with the age and growth of somatic indicators in boys not engaged in sports activities, there also occurs a progressive enhancement of the performance and general endurance of the body. The works by ${ }^{6,7}$ also demonstrate a manifold increase over age in the volume of work performed at the power of $\mathrm{PWC}_{170}$. However, if to judge by the growth rates, we can reveal the regularities that are inconsistent with the age-specific tendency.

For example, the boys not engaged in sports activities demonstrated the highest rates of the $\mathrm{PWC}_{170}$ and $\mathrm{VO}_{2}$ max indicators growth at the age of 11 and 15 years (Table 2). The minimal value of their $\mathrm{PWC}_{170}$ and $\mathrm{VO}_{2}$ max indicators growth for the entire studied period was observed at the age of 13 years in the setting of the adolescent growth spurt. 
It has been found out that the nature of changes in the growth promoting processes within the ontogeny has a significant effect on the age specific dynamics of the growth rates of physical performance and general endurance of the body: It is at the age of 11 and 15 years that the growth rates of the $\mathrm{PWC}_{170}$ и $\mathrm{VO}_{2}$ max indicators were the highest for the entire studied period against the background of significant reduction in the rates of the growth related processes. This is one of the manifestations of the basic growth and development characteristic, which was first noticed by3. Later it was confirmed by the studies of $^{8}$, and other authors ${ }^{4,6,9}$. According to these scholars, the reduction in the functional and adaptive capabilities of an organism occurs with the purpose of strengthening the growth related processes. This logic of maturation of the structural and functional properties in the ontogeny does not correspond to the entrenched concepts of physical performance as of a uniform process in the ontogenetic development of a child. According to the concept put forward by ${ }^{9}$ each age period consists of 2 phases: The first phase involves inhibition of growth and accumulation of qualitative changes; the second phase involves activation of growth processes against the background of qualitative stability. In the opinion of ${ }^{9}$, further progress in the development of this direction lies in searching for the regulatory and molecular mechanisms that determine both the sequence of the growth and differentiation phases and the synchronization of these processes in different tissues of the developing body.

Partially, the mechanism of this phenomenon was disclosed in the works $b^{6}{ }^{6}$ : During the periods of impairment of the growth related processes and activation of the differentiation processes, we can observe the enhanced development of the skeletal muscles mitochondrial apparatus, the sharp increase in the content of cytochrome $a$, which improves the efficiency of the biological oxidation in mitochondria, changes the energy status of the body, enhances its aerobic capacity, and creates a favorable physiological background for the $\mathrm{PWC}_{170}$ and especially $\mathrm{VO}_{2}$ max indicators growth.

A similar regularity of growth and development manifested itself in the conditions of sports training. Thus, the most significant growth of the $\mathrm{PWC}_{170}$ and $\mathrm{VO}_{2} \max$ indicators in the young football players was observed at the age of 13 and 15 years against the decrease in the rates of growth and enhancement of the differentiation processes. On the contrary, the lowest growth of the $\mathrm{PWC}_{170}$ and $\mathrm{VO}_{2}$ max indicators was observed at the age of 14 years against the adolescent growth spurt.

The most significant increase of physical performance in young basketball players was observed at the age of 12 and 15 years, and of the $\mathrm{VO}_{2}$ max indicator - at the age of 11 and 15 years. Meanwhile, the gain of physical performance at the age of 12 years took place against the

Table 2. The $(\mathrm{M} \pm \mathrm{m})$ indicators of the physical performance (PWC170, $\mathrm{kgm} / \mathrm{min} / \mathrm{kg}$ ) and general endurance (VO2max, $\mathrm{ml} / \mathrm{min} / \mathrm{kg}$ ) of the 10-15-year-old boys, who were and were not engaged in sports activities (football, basketball)

\begin{tabular}{|c|c|c|c|c|c|c|}
\hline \multirow[t]{2}{*}{ Age } & \multicolumn{2}{|c|}{ Non-athletes } & \multicolumn{2}{|c|}{ Football players } & \multicolumn{2}{|c|}{ Basketball players } \\
\hline & $\begin{array}{c}\mathrm{PWC}_{170} \\
(\mathrm{kgm} / \mathrm{min} / \mathrm{kg})\end{array}$ & $\begin{array}{c}\mathrm{VO}_{2} \max \\
(\mathrm{ml} / \mathrm{min} / \mathrm{kg})\end{array}$ & $\begin{array}{c}\mathrm{PWC}_{170} \\
(\mathrm{kgm} / \mathrm{min} / \mathrm{kg})\end{array}$ & $\begin{array}{c}\mathrm{VO}_{2} \max \\
(\mathrm{mlmin} / \mathrm{kg})\end{array}$ & $\begin{array}{c}\mathrm{PWC}_{170} \\
(\mathrm{kgm} / \mathrm{min} / \mathrm{kg})\end{array}$ & $\begin{array}{c}\mathrm{VO}_{2} \max \\
(\mathrm{mlmin} / \mathrm{kg})\end{array}$ \\
\hline 10 years & $9.9 \pm 0.1$ & $48.5 \pm 0.7$ & ${ }^{*} 14.0 \pm 0.05$ & $\star 55.0 \pm 0.3$ & $10.5 \pm 0.1^{*}$ & $48.3 \pm 0.7^{\star}$ \\
\hline 11 years & $11.5 \pm 0.1$ & $54.9 \pm 0.4$ & ${ }^{\star} 14.4 \pm 0.2$ & $\star 57.7 \pm 0.2$ & $11.9 \pm 0.4^{*}$ & $53.1 \pm 1.0^{\star}$ \\
\hline Growth rate $_{( \pm \%)}$ & $+16.1 \%$ & $+13.9 \%$ & $+3.3 \%$ & $+4.9 \%$ & +13.7 & +9.8 \\
\hline 12 years & $12.2 \pm 0.1$ & $55.1 \pm 0.7$ & ${ }^{\star} 14.2 \pm 0.3$ & $\star 52.6 \pm 0.6$ & * $14.6 \pm 0.3$ & *50.5 $\pm 0.9^{*}$ \\
\hline Growth rate $_{( \pm \%)}$ & $+6.0 \%$ & $+0.4 \%$ & $-1.9 \%$ & $-8.2 \%$ & +22.0 & $-4,7$ \\
\hline 13 years & $12.9 \pm 0.3$ & $54.5 \pm 0.6$ & ${ }^{\star} 16.1 \pm 0.2$ & $55.3 \pm 0.4$ & * $14.8 \pm 0.3$ & $\star 47.1 \pm 0.7^{\star}$ \\
\hline Growth rate $_{( \pm \%)}$ & $+5.7 \%$ & $-1.1 \%$ & $+14.1 \%$ & $+5.2 \%$ & +1.6 & -6.7 \\
\hline 14 years & $14.1 \pm 0.1$ & $54.8 \pm 0.2$ & ${ }^{\star} 16.3 \pm 0.2$ & $\star 52.6 \pm 0.4$ & ${ }^{\star} 16.0 \pm 0.2$ & ${ }^{\star} 48.3 \pm 0.4^{*}$ \\
\hline Growth rate $_{( \pm \%)}$ & $+9.5 \%$ & $+0.5 \%$ & $+0.6 \%$ & $-5 \%$ & +8.3 & +2.5 \\
\hline 15 years & $16.4 \pm 0.3$ & $56.0 \pm 0.6$ & ${ }^{\star} 19.2 \pm 0.1$ & ${ }^{\star} 60.7 \pm 0.4$ & ${ }^{\star} 18.1 \pm 0.4$ & $\star 52.0 \pm 0.5^{\star}$ \\
\hline Growth rate $_{( \pm \%)}$ & $+16.3 \%$ & $+2.2 \%$ & $+18.2 \%$ & $+15.5 \%$ & +12.9 & +7.6 \\
\hline $\begin{array}{l}n-\text { number of } \\
\text { measurements }\end{array}$ & \multicolumn{2}{|c|}{60} & \multicolumn{2}{|c|}{60} & \multicolumn{2}{|c|}{60} \\
\hline
\end{tabular}

The $(\mathrm{M} \pm \mathrm{m})$ indicators of the physical performance (PWC170,kgm/ $\mathrm{min} / \mathrm{kg}$ ) and general endurance $(\mathrm{VO} 2 \mathrm{max}, \mathrm{ml} / \mathrm{min} / \mathrm{kg}$ ) of the 10-15-year-old boys, who were and were not engaged in sports activities (football, basketball) 
significant enhancement of the growth related processes, i.e., during the period of an adolescent growth spurt. According to the works by ${ }^{9,10}$, during certain periods of ontogeny under the effect of the external or internal stimuli, the synchronization of the growth-related and differentiation processes may occur in various tissues of the body, which results in the fading of any contradictions between the processes of growth and development. In this regard, an important and significant factor is that in young basketball players under the age of 13 years, the unidirectional growth rates of the somatic and physical performance indicators were observed, i.e., the logics of somatic and functional development coincided, which levels the disintegration processes between shape and function. In practical terms, this allows us to provide a more successful way of solving the problem of loads rationing in basketball training at the age of 10-13 years.

During all the studied age periods, the young football players and the boys not engaged in sports activities were characterized by the contiguous dynamics of growth rates of the $\mathrm{PWC}_{170}$ and $\mathrm{VO}_{2} \max$ indicators. This is consistent with the data provided by ${ }^{11}$. However, there are works demonstrating that the $\mathrm{PWC}_{170}$ dynamics is not always consistent with the $\mathrm{VO}_{2}$ max dynamics12. Such disagreement in the dynamics of the $\mathrm{PWC}_{170}$ and $\mathrm{VO}_{2} \max$ indicators was detected by us only in the male basketball players at the age of 12 years. Apparently, it is related to the fact that the $\mathrm{PWC}_{170}$ indicator reflects something more than just the capacity of the aerobic energy system. The $\mathrm{PWC}_{170}$ indicator, to a greater extent than the $\mathrm{VO}_{2} \max$ indicator characterizes the vegetative component of adaptation, the degree of the regulatory systems' stress, and the reactivity of the cardiovascular system ${ }^{11}$.

In spite of the lowest definitive indicators of the somatic development, young football players demonstrated the highest $\mathrm{PWC}_{170}$ and $\mathrm{VO}_{2}$ max indicators (Table 2.) as compared to their peers, basketball players and non-athletes, due to the greater volume and harmonious combination of the aerobic and anaerobic loads throughout the entire academic training period ${ }^{13}$. It should be noted that the examined young football and basketball players had the $\mathrm{PWC}_{170}$ and $\mathrm{VO}_{2}$ max indicators significantly exceeding the standard values for this age, while the $\mathrm{PWC}_{170}$ and $\mathrm{VO}_{2}$ max development indicators of the boys not engaged in sports activities remained within the standard limits, which emphasizes the high efficiency of the sports activities in the CYSSOR mode necessary for the development of physical performance and endurance of a male organism ${ }^{4}$. An analysis of the data obtained by us and concerning the dependence of the somatic indicators of the young 14-15-year-old football players (6-7 years of sports experience) on the game role showed that the defenders, midfielders, and forwards had no significant differences in the body length $(\mathrm{P}>0.05)$, whereas the goalkeepers were significantly higher than their peers, especially regarding the forwards $(\mathrm{P}<0.05)$. On the one hand, the higher indicators of the goalkeepers' body length are substantiated by the initial selection, and on the other hand, by the lower motor density during the game.

The body weight indicators of the young football players with various game roles had also no fundamental differences $(\mathrm{P}>0.05)$, but at the same time, we revealed the trend of the body weight decrease from a defender to a midfielder and to a forward. This is quite logical, because the higher is the load on the playing field, the higher will be the stress of the energy supplying mechanisms. It is know that in children and adolescents, the fats are the dominant energy substrate ${ }^{11}$.

During the study of physical performance and general endurance, we revealed significant differences in the $\mathrm{PWC}_{170}$ and $\mathrm{VO}_{2}$ max indicators $(\mathrm{P}<0.05)$ between the goalkeepers and forwards, whereas between the players of other game roles, we managed to detect only one trend-the trend to increasing physical performance and general endurance from a goalkeeper to a defender and to a midfielder.

The study of somatic indicators in young basketball players of various game roles demonstrated no principal differences in terms of both body length and body weight between the defenders, forwards, and centers $(\mathrm{P}>0.05)$. However, the highest indicators of the body length were observed in the defenders who worked over the rim.

A comparative analysis showed that most enduring boys among the young basketball players were the forwards, who played behind the basket, arranged attacks, and made outside shots. Such high motor density during the game contributed to the development of a higher level of $\mathrm{PWC}_{170}$ and $\mathrm{VO}_{2}$ max values in the forwards. Among the 14-15-year-old basketball players, the centers were less enduring according to the PWC170 and VO2max indicators, even though their body length and weight indicators were higher.

Given that the intensive specialized training of young athletes and the final division into game roles usually begins at the age of 16-17 years, the identified 
by us differences in physical performance and general endurance among the young football and basketball players of various game roles are the foundation for their future success in a certain game role.

\section{Conclusion}

All the previously mentioned has led to the following conclusions:

- The determined regularities of the somatic development are less constant and stable in their time-response and quantitative characteristics. Under the sufficiently durable and strong effects of the sports physical activities, a time displacement of the adolescent growth spurt occurs towards the earlier or later age periods (towards the age of 12 years in young basketball players, and 14 years in young football players with regard to the age of 13 years, which is naturally predetermined by the ontogeny process in boys).

- In the conditions of football training, the sports physical activities can be considered as a growth promoting factor only at the early stages of the training process (10-11 years), since in this age period, the young football players had the highest body length and weight indicators among their peers-basketball players and non-athletes. The further growth promoting influence of football training is leveled by the increasing volume and intensity of sports physical activities, which results in that the young football players demonstrate the lowest definitive somatic indicators against the significantly higher indicators of $\mathrm{PWC}_{170}$ and MOC. The basketball training has a growth-promoting effect on the organism of young athletes throughout the entire training period under study. The clearest manifestation of the cumulative training effect is observed in the range from 12 to 15 years of age.

- The age dynamics of PWC $\mathrm{PW}_{170}$ and MOC in the young football players and male non-athletes is closely related to the dynamics of somatic development: During the periods of the increasing growth rates, the level of performance and general endurance of the body is reduced, and during the periods when the growth rates are inhibited, this level starts increasing, i.e., we observe a heterochronic nature of the body's functional fitness development. At the same time, the most significant periods in the development of the $\mathrm{PWC}_{170}$ and MOC indicators in young football players is the age of 13 and 15 years, and in the male non-athletes -11 and 15 years.
- In the conditions of basketball training under the age of 13 years, the logics of somatic and functional development coincide, when the growth and development processes are concomitant, and the organism equally provides for the growth and energy functions, i.e., there is a synchronization of the growth and differentiation processes, and the phenomenon of the intersystem heterochrony of development is leveled. However, the time convergence of the two development functions causes certain tension of the vegetative mechanisms of cardiac activity regulation, especially at the age of 12 years, as evidenced by the changes in the heart rate variability during the active orthostatic test performance.

\section{References}

1. Shakhanova AV, Kuzmin AA, Silantiev MN, Skhakumidov TA. Connection of exercise performance with somatic and sexual development, work-out session targeting in young football and basketball players aged 10-17. New Investigations. 2009; 2:121-2. [in Russian].

2. Peterhans E, Worth A, Woll A. Association between health behaviors and cardiorespiratory fitness in adolescents: Results from the cross-sectional momo-study. Journal of Adolescent Health. 2013 Aug; 53(2):272-9. Available from: 10.1016/j. jadohealth.2013.02.011

3. Shmalgauzen II. Growth and differentiation. Animal growth. Moscow-Leningrad: Biomediz; 1935. [in Russian].

4. Shakhanova AV. Extended motion mode impact on ontogenetic development and physical fitness of children and adolescents [PhD thesis]. Moscow; 1998. [in Russian].

5. Nikitiuk BA. Human body build. The science and technology results: Serial anthropology. VINITI. 1991; 4:3-149. [in Russian].

6. Kornienko IA, Sonkin VD. Age-related changes of energy metabolism and thermoregulation. Moscow: Nauka; 1979. [in Russian].

7. Bland J, Pfeiffer K, Eisenmann JC. The PWC170: Comparison of different stage lengths in 11-16 year olds. Eur J Appl Physiol. 2012 May; 112(5):1955-61. Available from: $10.1007 / \mathrm{s} 00421-011-2157-\mathrm{z}$

8. Boell EJ, Weber R. Cytochrome oxidase activity in mitochondria during amphibian development. Exp. Cell Res. 1955; 9:559-67.

9. Hermanussen M, Sonkin VD, et al. Growth variation, final height and secular trend. HOMO-Journal of Comparative Human Biology. 2010; 61:277-84.

10. Sonkin VD, Kornienko IA, Kozlov AI, et al. Fundamental laws of growth and physical development. In: Farber DA, Bezrukikh MM, editors. Physiology of Child Development. Guidelines for Age-Specific Physiology. Moscow: Moscow Psychologic and Social Institute Press; 2000. p. 43-131. [in Russian]. 
11. Kornienko IA, Sonkin VD. Ontogenesis of Energy Metabolism. In: Bezrukikh MM, Editor. Physiology of Child Development: Theoretical and Applied Aspects. Moscow: Obrazovanieot A do Ya; 2000. p. 142-8). [in Russian].

12. Nikolaidis PT. Association between body mass index, body fat per cent and muscle power output in soccer players. Central European Journal of Medicine. 2012 Dec; 7(6):7839. Available from: 10.2478/s11536-012-0057-1
13. Jastrzębski Z. Głowacki A, Ignatiuk W, Konieczna A. Training load structure of young soccer players in a typical training microcycle during the competitive and the transition period. Baltic Journal of Health and Physical Activity. 20113; 3(1). Available from: 10.2478/v10131-011-0003-7 